\title{
The burden of prostate cancer in Canada
}

\author{
Yves Fradet, MD, FRCSC; ; Laurence Klotz, MD, FRCSC; ${ }^{\dagger}$ John Trachtenberg, MD, FACS, FRCSC; ${ }^{\text {S }}$ \\ Alexandre Zlotta, MD, PhD, FRCSC
}

\begin{abstract}
The clinical and economic burden of prostate cancer in Canada is substantial, and is rising. Studies indicate that 1 in 7 men will develop prostate cancer during their lifetime, and another 1 in 27 will die because of it. It is estimated that 4300 Canadian men will die of prostate cancer in 2008. Age, family history, race and diet are all risks associated with the development of prostate cancer. A diagnosis of cancer carries a significant burden and like other cancers is a cause of significant anxiety and depression. Uncertainty regarding the value of screening for prostate cancer has been, and continues to be, a challenge for primary care physicians and urologists.
\end{abstract}

Can Urol Assoc J 2009;3(3Suppl2):S92-100

\section{Epidemiology of prostate cancer}

$\mathrm{P}$ rostate cancer is the most commonly diagnosed non-skin cancer among Canadian men, and is a significant cause of cancer-related death (Figure 1)..$^{1,2}$ In 2008, the Canadian Cancer Society estimated that 24700 new cases of prostate cancer would be diagnosed, constituting about $26 \%$ of all new male cancer cases, and that 4300 men would die of the disease. ' Currently, 1 in 7 men will develop prostate cancer during their lifetime, and 1 in 27 will die of it, a ratio of 1 death

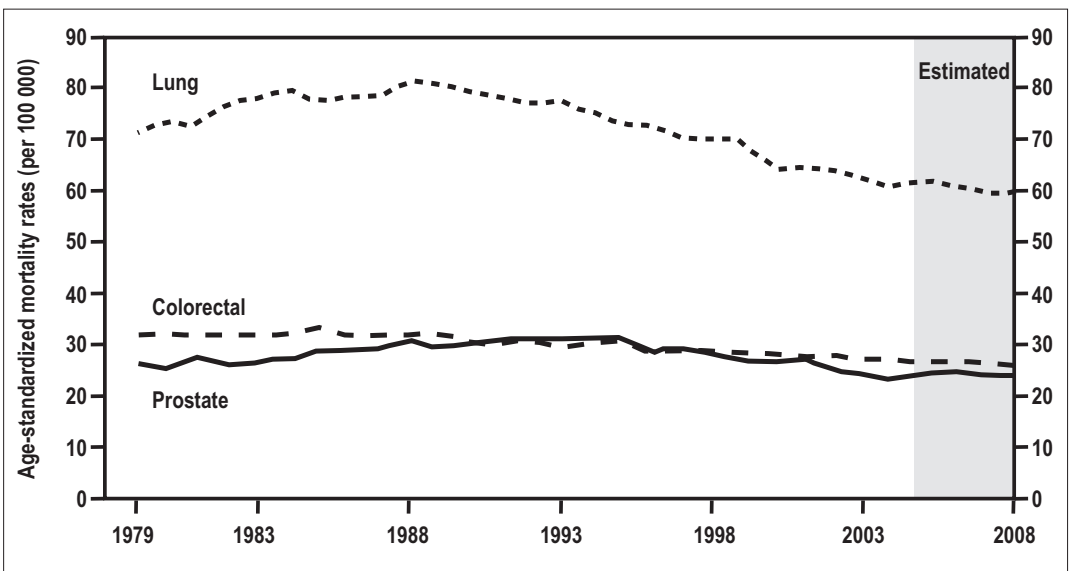

Fig. 1. Age-standardized mortality rates for prostate, lung and colorectal cancer in Canada, 1979-2008. Rates are standardized to the age distribution of the 1991 Canadian population. Rates for 2005 to 2008 are estimates. ${ }^{2}$ per 4 diagnosed, which is very similar to the ratio observed for breast cancer in women.

Between 1979 and 1990, the incidence of prostate cancer increased steadily in Canada at an average annual rate of approximately $3 \%{ }^{3}$ Since then, rates have changed substantially rapidly increasing from 1990 to 1993 (12.7\%), declining sharply from 1993 to 1995 (8.4\%), and increasing again, albeit modestly, since 1996 (Figure 2). ${ }^{2,3}$ The rate peaked in 1993 at 140.5 incident cases per 100000 men and again in 2001 at 132.4 per $100000 .^{1,2}$ These peaks in large part reflect the increase in early detection of prostate cancer secondary to the introduction of the prostate-specific antigen (PSA) blood test. The first, in 1993, follows the introduction of PSA as a screening tool; the second, in 2001, is best explained by the publicity around Allan Rock's - then Canada's Minister of Health - diagnosis of early prostate cancer as a result of serial PSA testing. ${ }^{1,2}$ An incidence rate of 129.0 per 100000 was estimated for 2008 by the Canadian Cancer Society. ${ }^{2}$

The trends in mortality are less clear-cut. Mortality changes are not of the same magnitude as changes in incidence and, in fact, the mortality has declined more in later years than the incidence. ${ }^{1,2}$ Canadian age-standardized prostate cancer mortality rates increased significantly, at a rate of $1.4 \%$ per year from 1977 to 1993, than decreased significantly, at an average rate of $2.7 \%$ per year from 1993 to 1999, and have continued declining ever since (Figure 1). The rate peaked in 1991 at 31.2 deaths per 100000 men but is estimated by the Canadian Cancer Society to be 23.6 per 100000 for 2008, an impressive 24.3\% mortality decline in 17 years despite a significant increase in men's lifetime expectancy during the same period. ${ }^{1-3}$ This remarkable progress is likely due to the earlier diagnosis and treatment of prostate cancer. Unfortunately, it comes at the expense of an increased incidence 
of men being diagnosed with prostate cancer of whom a significant proportion are at little risk of having a life-threatening disease during their lifetime. ${ }^{4}$

\section{Risk factors}

\section{Age}

Age is a well-known, significant risk factor for prostate cancer, and although precancerous lesions have been detected in men under the age of $40,{ }^{5}$ it is not until the age of 50 that the incidence rate rises sharply (Figure 3). ${ }^{1}$ In fact, the incidence of prostate cancer increases faster with age than that of any other major cancer. ${ }^{1}$ The rate of prostate cancer diagnosis in Canada is approximately 100 per 100000 men aged 50 to 54, 500 per 100000 men aged 60 to 64 and greater than 700 per 100000 men over the age of $80 .^{1}$ Prostate cancer theoretically may result, among other factors, from an increase in oxidative stress as a result of aging, but supportive evidence is lacking. ${ }^{6}$

\section{Family history}

Following the first report of familial aggregation of prostate cancer in 1956, ${ }^{7}$ several epidemiologic studies on family history as a risk factor have shown an increased risk of prostate cancer for brothers and sons of men with the disease. ${ }^{7,8}$ Men whose fathers or brothers had prostate cancer are typically diagnosed 6 to 7 years earlier than men with no family history of the disease (Table 1). ${ }^{9}$ Men who have 3 or more relatives with prostate cancer have a $35 \%$ to $45 \%$ risk of developing prostate cancer (Table 1). Men whose fathers had prostate cancer before age 60 years have a $20 \%$ chance of developing the disease, compared with $8 \%$ for men without a similar history (Table 1 ). The risk is slightly greater for men whose brothers had prostate cancer than for those whose fathers had the disease. More than $40 \%$ of the cases in men diagnosed with prostate cancer before the age of 55 years may be due to heredity (Table 1). It has also been noted that the age at diagnosis is 6 years younger in men with hereditary prostate cancer than those who did not inherit the disease. This compares with a 20-year difference between other inherited cancers (such as ovary, breast, and colon) compared to the sporadic cases of the same cancers. A study of 44788 pairs of twins listed in the Swedish, Danish and

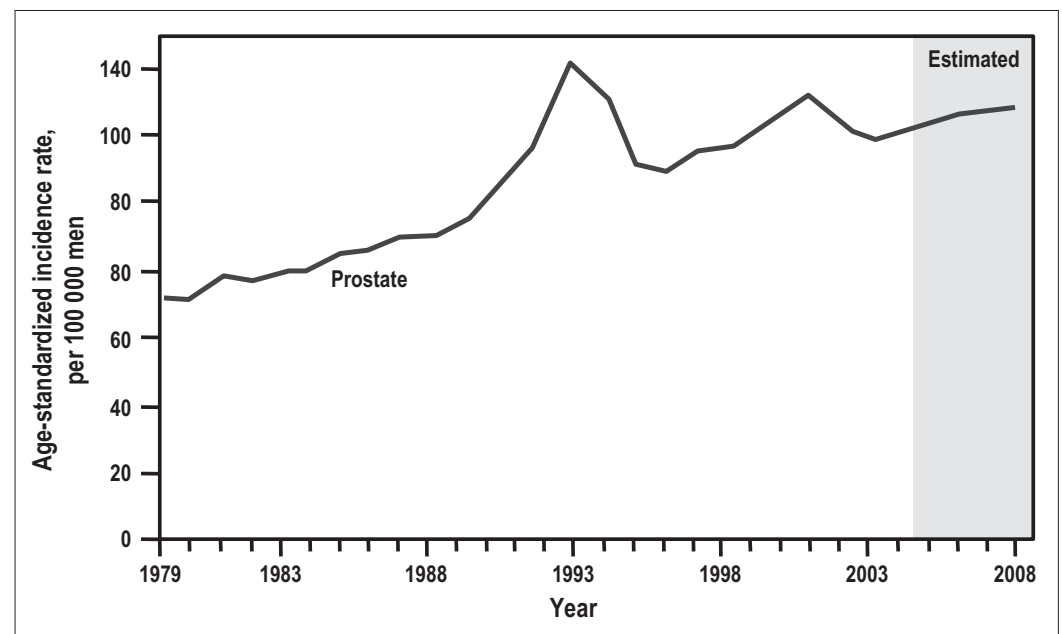

Fig. 2. Age-standardized incidence rates for prostate cancer in Canada, 1979 to 2008. Rates are standardized to the age distribution of the 1991 Canadian population. Rates for 2005 to 2008 are estimates. ${ }^{2}$

Finnish twin registries found that inherited genetic factors make a minor contribution to susceptibility to most types of neoplasms, including prostate cancer, and indicated that environment played the principal role in causing sporadic cancers. ${ }^{10}$ Thus, environmental factors may also be of importance in families with hereditary prostate cancer. Early-detection bias may account for some of these findings; however, most studies of family history and prostate cancer were conducted before the widespread use of PSA screening. ${ }^{6}$

\section{Genetics}

Approximately $5 \%$ to $10 \%$ of cases of prostate cancer may be caused by inherited dominant susceptibility factors. Thirty percent to $40 \%$ of early onset disease may also be attributed to these factors. ${ }^{8}$ High

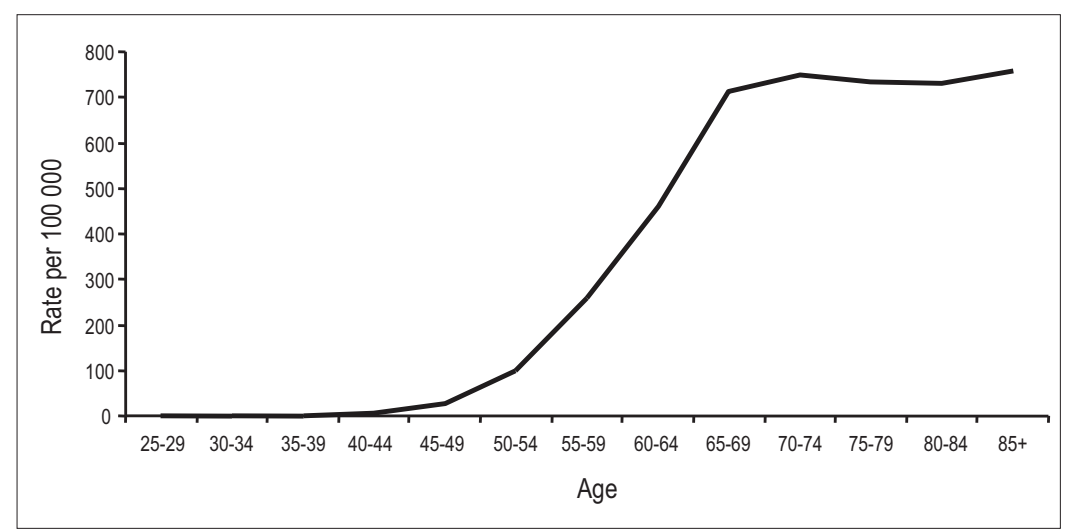

Fig. 3. Cancer incidence by age group, Canada, 2004. Rates are standardized to the age distribution of the 1991 Canadian population.' 
Fradet et al.

Table 1. Family history and prostate cancer risk

\section{Family History}

No prostate cancer

Father diagnosed at or after age 60

1 brother diagnosed at or after age 60

Father diagnosed before age 60

1 brother diagnosed before age 60

2 male relatives* with prostate cancer

3 or more male relatives with prostate cancer

Relative risk = increase in risk in comparison to men with no family history of prostate cancer; Lifetime risk = overall chance of developing prostate cancer during a man's lifetime; * father and brother, or 2 brothers, or a brother and a maternal grandfather or uncle, or a father and a paternal grandfather or uncle. Adapted from Acta genetica et statistica medica. ${ }^{14}$

penetrance and low penetrance susceptibility genes are likely to be involved. More than a half dozen chromosome loci that may contain such genes have been mapped. ${ }^{9}$ More recent genome-wide association studies have established robust associations of common variants at five genetic loci with prostate cancer. ${ }^{11,12}$ Genome-wide scans identified single nucleotide polymorphisms associated with higher risk $(20 \%$ to $50 \%)$ in various loci, especially 8 q 24 , $17 q 12$ and $12 q 24$. Specific genes for which there is some evidence of a causal relationship to prostate cancer include those that code for the enzyme 5 -alpha-reductase (5AR), which converts testosterone to dihydrotestosterone (DHT), androgen receptors and their variants, growth factors, and tumour suppressor genes. Some evidence suggests that the breast cancer susceptibility gene, BRCA, also influences prostate cancer risk. ${ }^{13}$

\section{Race}

The risk of prostate cancer is dramatically higher among African-American men than in men of any other race. ${ }^{14}$ For the period 2001 to 2005 , racespecific incidence rates in the United States ranged from 248.5 per 100000 for blacks, 156.7 per 100000 for whites, 138.0 per 100000 for Hispanics, 93.8 per 100000 for Asian/Pacific Islanders, and 73.3 per 100000 for American/

\section{Table 2. SEER incidence rates by race}

\begin{tabular}{lc}
\hline Race / Ethnicity & Age-adjusted Rate (per $\mathbf{1 0 0 0 0 0 ~} \mathbf{~ m e n )}$ \\
All races & 163.0 \\
White & 156.7 \\
Black & 248.5 \\
Asian/Pacific Islander & 93.8 \\
American Indian/Alaskan Native & 73.3 \\
Hispanic & 138
\end{tabular}

Rates are based on cases diagnosed in 2001-2005 from 17 Surveillance Epidemiology and End Results (SEER) geographic areas. Adapted from the United Sates National Institutes of Health. ${ }^{14}$
Alaskan Natives (Table 2).${ }^{14}$ African-American men are also more likely to be diagnosed at an advanced stage, ${ }^{15}$ and are twice as likely to die of prostate cancer than white men (59.4 per 100000 for blacks and 24.6 per 100000 for whites). ${ }^{13,14}$ Race-related differences in prostate cancer risk may reflect multiple factors associated with race. ${ }^{7,16}$ Whittemore et al. showed that African-American men have a higher intake of dietary fat, and that this could contribute to their higher risk. ${ }^{17}$ By contrast, Japanese men consume a relatively low-fat diet. ${ }^{17}$ Access to proper health care and other socioeconomic factors may place African-Americans at a higher risk for poorer disease outcomes than white men but does not explain the higher incidence rate. ${ }^{18}$

\section{Diet}

In a review of 23 published case-control studies that examined the relationship between prostate cancer and dietary fat, over $50 \%$ reported a statistically significant relationship or trend towards significance. ${ }^{19}$ Others have shown that the risk of prostate cancer progression to an advanced stage is greater in men with a high-fat diet. ${ }^{20}$ Although the data on the association between obesity and prostate cancer incidence are contradictory, obesity has been consistently associated with an increased risk of prostate cancer aggressiveness and mortality. ${ }^{21}$ Higher intakes of calcium and dairy products, a major source of dietary calcium, are reported to increase the risk of prostate cancer. ${ }^{22}$

\section{Hormonal and sexual factors}

High testosterone levels, vasectomy and history of frequent sexual activity have been studied, but not found to increase risk of prostate cancer. ${ }^{23}$

\section{Smoking}

Smoking may not increase the risk of prostate cancer, but new evidence suggests it may encourage tumour growth in prostate cancer patients. Recent reports have found that smoking at the time of diagnosis, compared with never smoking, was associated with a significant increase in risk of prostate cancer-specific mortality. ${ }^{24}$

\section{Chemical exposure}

People exposed to certain chemicals such as pesticides and herbicides may have higher-than- 
average rates of prostate cancer. Methyl bromide, a pesticide, has been linked to increased prostate cancer among exposed farm workers. ${ }^{25}$

\section{Micronutrients}

Studies have found a number of micronutrients that appear to reduce the risk of prostate cancer, including soy (isoflavones), green tea and tomatoes (lycopene). ${ }^{16,23}$ A recent review of study data from SELECT (the Selenium and Vitamin E Cancer Prevention Trial), showed that selenium and vitamin E supplements, taken either alone or together for an average of five years, did not prevent prostate cancer. ${ }^{26}$ Previous studies had suggested otherwise..$^{27-29}$

\section{Diagnosis, treatment and quality of life}

The use of the PSA blood test has resulted in significant increases in the number of men who are diagnosed at both a younger age and at an early stage of the disease. Initial reports from two large, randomized trials designed to assess the effect of PSA screening yielded conflicting results. ${ }^{30,31}$ In the U.S. Prostate, Lung, Colorectal and Ovarian (PLCO) Cancer Screening Trial, Andriole et al. reported no mortality benefit from combined screening with PSA testing and digital rectal examination (DRE) during a median follow-up of 11 years..$^{30}$ In contrast, the European Randomized Study of Screening for Prostate Cancer (ERSPC) trial reported a 20\% relative reduction in the risk of death from prostate cancer at a median follow-up of 9 years for men who underwent PSA screening without DRE. ${ }^{31}$ This translates to an absolute reduction of about 7 prostate cancer deaths per 10000 men screened. PSA-based screening was also associated with a high risk of overdiagnosis. The ERSPC investigators therefore cautioned that the introduction of populationbased screening must take into account population coverage, overdiagnosis, overtreatment, quality of life, cost and cost-effectiveness. ${ }^{31}$

As with other forms of cancer, being diagnosed with prostate cancer leads to anxiety, but not to the same extent in every patient. ${ }^{32}$ Previous studies have documented that approximately one-third of all cancer patients will experience significant levels of distress associated with diagnosis, which warrants psychosocial treatment. ${ }^{33}$ Anxiety among cancer patients may heighten as the disease progresses or as treatment becomes more aggressive. ${ }^{34}$ Patients who have problems communicating with their loved ones and physicians are more at risk of developing anxiety. ${ }^{34}$ Carlson et al. reported that some 30\% of prostate cancer patients met the criteria for general distress in the clinical range. ${ }^{33}$ Balderson and colleagues reported that of 94 men with prostate cancer who were seeking psychological support, $38 \%$ met the criteria for severe psychological distress. ${ }^{35}$ Lintz et al. reported higher levels of anxiety in men younger than 65 years of age with prostate cancer. ${ }^{36}$ Several instruments have been developed to help identify men with high anxiety, including the Memorial Anxiety Scale for Prostate Cancer (MAX-PC), ${ }^{37}$ the Hospital Anxiety and Depression Scale (HADS) ${ }^{38}$ and, more recently, the State-Trait Anxiety Inventory (state version) (STAIState)..$^{39}$ In a recent STAI-State study, $28 \%$ of prostate cancer patients at the pre-treatment stage were classed as "high anxiety", but the level of anxiety decreased significantly post-treatment. Those treated with prostatectomy reported less depression than those treated with radiotherapy ${ }^{39}$ Hervouet et al. also found that patients who initially received surgery were less likely to report clinical levels of depression and fatigue while those patients who initially received radiotherapy had higher levels of depression, anxiety and fatigue and were more likely to report clinical levels of depression and fatigue..$^{40}$

Health-related quality of life (HRQOL) outcomes have been shown to differ among radical prostatectomy, external beam radiation therapy and brachytherapy. In a study of 580 men with localized prostate cancer, urinary control and sexual function were better after external beam radiation therapy. Both forms of radiation caused more bowel dysfunction, while brachytherapy resulted in more obstructive and irritative symptoms. ${ }^{41}$ In a recent study of 212 patients with localized prostate cancer, those who underwent brachytherapy experienced worse global health scores and a trend toward lower functional-scale and symptom-scale scores in the first year following operation compared with those who underwent radical prostatectomy. ${ }^{42}$ However, these scores improved in all subsequent years of follow-up. Only diarrhea was temporarily worse in the second year following brachytherapy compared with radical prostatectomy. Mean total IPSS and QOL scores were not significantly different between the two groups.

Stress and anxiety after receiving a diagnosis of prostate cancer may trigger cardiovascular events. ${ }^{43}$ Fang reported that men were at a 50\% elevated risk of fatal cardiovascular events in the year after diagnosis and a 30\% greater risk of a 
Fradet et al.

nonfatal event. Events were most likely in the first week after diagnosis and in younger men and those without cardiovascular risk factors. ${ }^{43}$ It has been recommended that clinicians attempt early detection of patients at risk of high levels of anxiety and depression after prostate cancer diagnosis. ${ }^{39}$ Recommendations have also been made to target interventions at treatment decision-related distress for all men and to offer in-depth psychosocial support for those who experience ongoing difficulties. ${ }^{44}$ Cancer-specific psychological distress also appears to be related to changes in PSA levels, and this distress influences treatment strategies. Physicians should seek to involve their patients and partners in treatment decision making concurrent with decision and psychological support. ${ }^{44}$

At present, there are insufficient data to recommend for, or against, screening for prostate cancer in men at average risk for developing the disease. $^{30,31}$ Screening for and treating disease at an early stage has been proposed to reduce the risk of dying of prostate cancer; however, there is insufficient evidence to determine whether screening for prostate cancer reduces the number of deaths. According to the recent European Randomized Study of Screening for Prostate Cancer, 1410 men would need to be screened and 48 additional cases of prostate cancer would need to be treated to prevent one death from prostate cancer. ${ }^{31}$

Interestingly, prostate biopsy might predispose to higher mortality rates.$^{45}$ Gallina et al. showed prostate biopsy to be associated with higher overall mortality than that observed in men unexposed to biopsy, and that the risk of death at 120 days after biopsy increases with age and Charlson comorbidity index (120-day mortality after biopsy was $1.3 \%$ v. $0.3 \%$ in controls). ${ }^{45}$ The certainty of this association, however, remains to be proven. In the ERSPC, no deaths were attributed to biopsy. ${ }^{31}$

Radical prostatectomy has been clearly shown to be superior to no treatment in reducing prostate cancer mortality and overall mortality in a randomized trial performed in Sweden. ${ }^{46,47}$ In this largely unscreened population, the reducion in diseasespecific mortality as a result of radical prostatectomy was greatest among patients younger than 65 years. A survival advantage has also been shown for the addition of radiotherapy to androgen ablation for men with high-risk prostate cancer. ${ }^{48}$ Among 875 patients with locally advanced or high-risk local prostate cancer, those who underwent local radiotherapy in addition to endocrine treatment experienced half the 10-year prostate cancer-spe- cific mortality rate, and substantially decreased overall mortality, compared with those who received only endocrine treatment. ${ }^{48}$

Moreover, there is increasing literature that provides information on risk factors for cancer progression. More men are seeking treatment and thus living with possible short- and long-term side effects of such treatment. ${ }^{41}$ Existing treatments, although potentially curative, can have side effects that can affect the quality of life among prostate cancer patients. ${ }^{49,50}$ Some experts feel that the single most important factor in determining an individual's optimal treatment strategy should be the patient's individual preference in association with possible side effects and complications of treatment. ${ }^{51}$ It has been estimated that over 800 articles addressing prostate treatment and the quality of life of the patient have been published. ${ }^{32}$ In a study by Crawford and colleagues, $42 \%$ of patients defined effective treatment as one that extended expected survival, or delayed disease progression, whereas $45 \%$ indicated that effectiveness meant the preservation of the quality of life. ${ }^{52}$ Several studies have noted that, although the majority of patients are concerned when asked about side effects, the issue has little impact on their final treatment decision. ${ }^{53}$ Patient-education materials on early-stage prostate cancer treatment have also been shown to be biased toward active treatment and do not contain comprehensive information about side effects and their potential impact on quality of life. ${ }^{54}$ Incontinence and impotence are by far the most commonly stated factors when making prostate cancer treatment decisions. Whereas incontinence appears to influence the decisions of approximately half of patients, impotence is reported less often. ${ }^{53}$ FeldmanStewart et al. found that urinary and bowel functions were the only 2 factors ranked important by greater than $50 \%$ of patients. ${ }^{55}$ Furthermore, fewer than $20 \%$ of men ranked sexual function as 1 of the top 3 factors important to their decision, despite $32 \%$ mentioning that it was important to them. ${ }^{55}$

\section{The economic burden}

The economic burden of this disease is substantial and has increased because of the PSA era. Grover et al. estimated the total economic burden of the disease in a cohort of 5.8 million Canadian men between 40 and 80 years old. ${ }^{56}$ According to their projections, prostate cancer would be diagnosed in an estimated 701,491 men (12.1\%) over their lifetimes. Direct medical costs would total $\$ 9.76$ billion or $\$ 3.89$ billion when discounted 5\% annually. The 
authors concluded that these data emphasize the need to define which treatment is the most effective in reducing the morbidity and mortality associated with this form of cancer..$^{56}$

In 2000, the total medical expenditure for prostate cancer treatment in the United States was $\$ 1.3$ billion - a 30\% increase over the total expenditure for $1994 .{ }^{57}$ Wilson and colleagues demonstrated that financial burden related to prostate management over 5 years is substantial and that, on average, annual costs are $\$ 7740$ and range from $\$ 5843$ for watchful waiting to $\$ 12590$ for androgen deprivation therapy ${ }^{58}$ Cumulative mean cost over 5.5 years for all risk groups was $\$ 42$ 570. Watchful waiting cost the least (\$32 135), whereas the highest costs were associated with androgen deprivation therapy (\$69 244). ${ }^{58}$

With an estimated 24700 Canadian men being diagnosed with prostate cancer and 4300 dying because of it, ${ }^{2}$ an effective prostate cancer prevention strategy could substantially reduce overall cancer-related costs. However, given the natural history of treated prostate cancer, the implementation of such a program would require an inexpensive medication with substantial cancer-risk reduction in order to be cost-effective. ${ }^{59}$ Svatek et al. recently demonstrated that chemoprevention with finasteride may be cost-effective when taking into consideration adjustments for the impact on the quality of life in high-risk populations such as men with highgrade prostatic intraepithelial neoplasia, or men with a family history of the disease. ${ }^{60}$ This model found that chemoprevention with finasteride increased quality-adjusted life years (QALYs) by 74 per 1000 men (29 days per individual). ${ }^{60}$ While this gain appears small, it is not insignificant according to Wright and Weinstein, who showed that a 1 -month gain in life expectancy is considered large. ${ }^{61}$ By comparison, cost-effective modeling for tamoxifen in breast cancer chemoprevention (a strategy that is not widespread in Canada) found tamoxifen to increase survival outcomes by 42 days for women aged 50 and 27 days for women aged $60 .{ }^{62}$

\section{Future challenges}

The clinical and economic burden of prostate cancer in Canada is substantial, and is rising. Studies indicate that prostate cancer will be diagnosed in over $14 \%$ of Canadian men and will be fatal in $3 \%$ to $4 \%$ of cases. Epidemiologic studies have provided, and continue to provide, valuable data on the risks associated with the development of prostate cancer. A diagnosis of cancer carries a sig- nificant burden, and a reduction in the risk of prostate cancer could be very valuable to society. A better understanding of the interplay of the genetic and environmental factors will allow for the design of new therapeutic strategies to abet the progression of prostate carcinogenesis.

It is intuitive to think that early detection of prostate cancer will lead to earlier and more effective therapy; however, there is limited evidence to support this statement. Future studies to help clarify the relationship between histologic and clinically evident prostate cancer and the true effect of PSA screening on prostate cancer mortality are necessary.

*Professor of Surgery/Urology, Department of Urology, Laval University, Quebec, QC; 'Professor, Department of Surgery, University of Toronto, Toronto, ON; \$Professor of Surgery and Medical Imaging, University of Toronto, Toronto, ON; : Professor, Department of Surgery (Urology), University of Toronto, Toronto, ON.

This article has been peer reviewed.

Competing interests: None declared.

\section{References}

1. Public Health Agency of Canada. Cancer Surveillance Online. http://dsol-smed. phac-aspc.gc.ca/dsol-smed/cancer. Accessed July 16, 2008.

2. Canadian Cancer Society/National Cancer Institute of Canada. Canadian Cancer Statistics. http://www.cancer.ca. Accessed October 16, 2008.

3. McDavid K, Lee J, Fulton JP, et al. Prostate cancer incidence and mortality rates and trends in the United States and Canada. Public Health Rep 2004;119:174-86.

4. Damber JE, Aus G. Prostate cancer. Lancet 2008;371:1710-21

5. Meyer F, Moore L, Bairati I, et al. Downward trend in prostate cancer mortality in Quebec and Canada. J Urol 1999;161:1189-91.

6. Sakr WA, Haas GP, Cassin BF, et al. The frequency of carcinoma and intraepithelial neoplasia of the prostate in young male patients. J Urol 1993;150:379-85.

7. Bostwick DG, Burke HB, Diakiew D, et al. Human prostate cancer risk factors. Cancer 2004;101 (10 Suppl):2371-490.

8. Bratt 0. Hereditary prostate cancer: clinical aspects. J Urol 2002;168:906-13.

9. Morganti G, Gianferrari L, Cresseri A, et al. Clinico-statistical and genetic research on neoplasms of the prostate. Acta Genet Stat Med 1956-1957;6(2):304-5.

10. Lichtenstein P, Holm NV, Verkasalo PK, et al. Environmental and heritable factors in the causation of cancer-analyses of cohorts of twins from Sweden, Denmark, and Finland. N Engl J Med 2000;343:78-85.

11. Sun J, Chang BL, Isaacs SD, et al. Cumulative effect of five genetic variants on prostate cancer risk in multiple study populations. Prostate 2008;68:1257-62.

12. Zheng SL, Sun J, Wiklund F, et al. Cumulative association of five genetic variants with prostate cancer. N Engl J Med 2008;358:910-9.

13. Rosen EM, Fan S, Goldberg ID. BRCAl and prostate cancer. Cancer Invest 2001;19:396412.

14. United States National Institutes of Health. National Cancer Institute Surveillance Epidemiology and End Results (SEER) data. www.seer.cancer.gov. Accessed July 18, 2008.

15. Hoffman RM, Gilliland FD, Eley JW, et al. Racial and ethnic differences in advancedstage prostate cancer: the Prostate Cancer Outcomes Study. J Natl Cancer Inst 2001;93:388-95.

16. Fleshner N, Zlotta AR. Prostate cancer prevention: past, present, and future. Cancer 2007:110:1889-99.

17. Whittemore AS, Kolonel LN, Wu AH, et al. Prostate cancer in relation to diet, physical activity, and body size in blacks, whites, and Asians in the United States and Canada. J Natl Cancer Inst 1995;87:652-61. 
18. Optenberg SA, Thompson IM, Friedrichs P, et al. Race, treatment, and long-term survival from prostate cancer in an equal-access medical care delivery system. JAMA 1995; 274:1599-605.

19. Fleshner N, Bagnell PS, Klotz L, et al. Dietary fat and prostate cancer. J Urol 2004;171 (2 Pt 2):S19-24

20. Bairati I, Meyer F, Fradet Y, et al. Dietary fat and advanced prostate cancer. J Urol 1998; 159:1271-5

21. Hsing AW, Sakoda LC, Chua S Jr. Obesity, metabolic syndrome, and prostate cancer. Am J Clin Nutr 2007;86:8843-57.

22. Gao X, LaValley MP, Tucker KL. Prospective studies of dairy product and calcium intakes and prostate cancer risk: a meta-analysis. J Natl Cancer Inst 2005;97:1768-77.

23. Gallagher RP, Fleshner N. Prostate cancer: 3 . Individual risk factors. CMAJ 1998; 159:807-13.

24. Gong Z, Agalliu I, Lin DW, et al. Cigarette smoking and prostate cancer-specific mortality following diagnosis in middle-aged men. Cancer Causes Control 2008;19:25-31.

25. Alavanja MC, Samanic C, Dosemeci M, et al. Use of agricultural pesticides and prostate cancer risk in the Agricultural Health Study cohort. Am J Epidemiol 2003;157:800-14.

26. Lippman SM, Klein EA, Goodman PJ, et al. Effect of selenium and vitamin E on risk of prostate cancer and other cancers: the Selenium and Vitamin E Cancer Prevention Trial (SELECT). JAMA 2009;301:39-51.

27. Knekt $P$, Albanes $D$, Seppänen $R$, et al. Dietary fat and risk of breast cancer. Am J Clin Nutr 1990;52:903-8.

28. Schrauzer GN, White DA, Schneider CJ. Cancer mortality correlation studies-III: statistical associations with dietary selenium intakes. Bioinorg Chem 1977;7:23-31.

29. van den Brandt PA, Zeegers MP, Bode P, et al. Toenail selenium levels and the subsequent risk of prostate cancer: a prospective cohort study. Cancer Epidemiol Biomarkers Prev 2003;12:866-71.

30. Andriole GL, Grubb RL 3rd, Buys SS, et al; PLCO Project Team. Mortality results from a randomized prostate-cancer screening trial. N Engl J Med 2009;360:1310-9.

31. Schröder FH, Hugosson J, Roobol MJ, et al; ERSPC Investigators. Screening and prostatecancer mortality in a randomized European study. N Engl J Med 2009;360:1320-8.

32. Visser $A$, van Andel $G$. Psychosocial and educational aspects in prostate cancer patients. Patient Educ Couns 2003;49:203-6.

33. Carlson LE, Angen M, Cullum J, et al. High levels of untreated distress and fatigue in cancer patients. Br J Cancer 2004;90:2297-304.

34. National Cancer Institute and U.S.National Institutes of Health. Anxiety Disorder. http://www.cancer.gov/cancertopics/pdq/supportivecare/anxiety/healthprofessional. Accessed November 2, 2008.

35. Balderson N, Towell T. The prevalence and predictors of psychological distress in men with prostate cancer who are seeking support. Br J Health Psychol 2003;8(P† 2):125-34.

36. Lintz K, Moynihan C, Steginga S, et al. Prostate cancer patients' support and psychological care needs: Survey from a non-surgical oncology clinic. Psychooncology 2003; 12:769-83.

37. Roth AJ, Rosenfeld B, Kornblith AB, et al. The memorial anxiety scale for prostate cancer: validation of a new scale to measure anxiety in men with prostate cancer. Cancer 2003:97:2910-8.

38. Nordin K, Berglund G, Glimelius B, et al. Predicting anxiety and depression among cancer patients: a clinical model. Eur J Cancer 2001;37:376-84.

39. Korfage IJ, Essink-Bot ML, Janssens AC, et al. Anxiety and depression after prostate cancer diagnosis and treatment: 5-year follow-up. Br J Cancer 2006;94:1093-8.

40. Hervouet S, Savard J, Simard S, et al. Psychological functioning associated with prostate cancer: cross-sectional comparison of patients treated with radiotherapy, brachytherapy, or surgery. J Pain Symptom Manage 2005;30:474-84.

41. Litwin MS, Gore JL, Kwan L, et al. Quality of life after surgery, external beam irradiation, or brachytherapy for early-stage prostate cancer. Cancer 2007;109:2239-47.

42. Wyler SF, Engeler DS, Seelentag W, et al. Health-related quality of life after radical prostatectomy and low-dose-rate brachytherapy for localized prostate cancer. Urol Int 2009;82:17-23
43. Fang, F. Cardiovascular events among newly diagnosed prostate cancer patients. San Francisco, CA USA. Abstract 12 American Society of Clinical Oncology Genitourinary Cancers Symposium Meeting. 2008.

44. Steginga SK, Turner E, Donovan J. The decision-related psychosocial concerns of men with localised prostate cancer: targets for intervention and research. World I Urol 2008:26:469-74

45. Gallina A, Suardi N, Montorsi F, et al. Mortality at 120 days after prostatic biopsy: a population-based study of 22,175 men. Int J Cancer 2008;123:647-52.

46. Bill-Axelson A, Holmberg L, Filén F, et al; Scandinavian Prostate Cancer Group Study Number 4. Radical prostatectomy versus watchful waiting in localized prostate cancer: the Scandinavian prostate cancer group-4 randomized trial. J Natl Cancer Inst 2008;100:1144-54

47. Bill-Axelson A, Holmberg L, Ruutu M, et al; Scandinavian Prostate Cancer Group Study No. 4. Radical prostatectomy versus watchful waiting in early prostate cancer. N Engl $J$ Med 2005;352:1977-84.

48. Widmark A, Klepp 0, Solberg A, et al; Scandinavian Prostate Cancer Group Study 7; Swedish Association for Urological Oncology 3. Endocrine treatment, with or without radiotherapy, in locally advanced prostate cancer (SPCG-7/SFUO-3): an open randomised phase III trial. Lancet 2009;373:301-8.

49. Shah NL, Sanda MG. Quality of life affecting treatment decisions for prostate cancer. Cancer News May 2002. http://www.cancernews.com/data/Article/225.asp. Accessed February 23, 2009.

50. US Department of Health and Human Services, CDC. Prostate Cancer: Can we reduce deaths and preserve quality of life? At-a-glance 2000.

51. Jani $A B$, Hellman $S$. Early prostate cancer: clinical decision-making. Lancet 2003;361:1045-53.

52. Crawford ED, Bennett CL, Stone NN, et al. Comparison of perspectives on prostate cancer: analyses of survey data. Urology 1997;50:366-72.

53. Zeliadt SB, Ramsey SD, Penson DF, et al. Why do men choose one treatment over another?: a review of patient decision making for localized prostate cancer. Cancer 2006;106:1865-74

54. Fagerlin A, Rovner D, Stableford S, et al. Patient education materials about the treatment of early-stage prostate cancer: a critical review. Ann Intern Med 2004;140:721-8.

55. Feldman-Stewart D, Brundage MD, Van Manen L, et al. Patient-focussed decisionmaking in early-stage prostate cancer: insights from a cognitively based decision aid. Health Expect 2004;7:126-41.

56. Grover SA, Coupal L, Zowall H, et al. The economic burden of prostate cancer in Canada: forecasts from the Montreal Prostate Cancer Model. CMAJ 2000;162:987-92.

57. Penson DF, Chan JM; Urologic Diseases in America Project. Prostate cancer. J Urol 2007;177:2020-9.

58. Wilson LS, Tesoro R, Elkin EP, et al. Cumulative cost pattern comparison of prostate cancer treatments. Cancer 2007;109:518-27.

59. Svatek RS, Lee JJ, Roehrborn CG, et al. The cost of prostate cancer chemoprevention: a decision analysis model. Cancer Epidemiol Biomarkers Prev 2006;15:1485-9.

60. Svatek RS, Lee JJ, Roehrborn CG, et al. Costefffectiveness of prostate cancer chemoprevention: a quality of life-years analysis. Cancer 2008; 112:1058-65.

61. Wright JC, Weinstein MC. Gains in life expectancy from medical interventionsstandardizing data on outcomes. N Engl J Med 1998;339:380-6.

62. Grann VR, Sundararajan V, Jacobson JS, et al. Decision analysis of tamoxifen for the prevention of invasive breast cancer. Cancer J 2000;6:169-78.

Correspondence: Dr. Yves Fradet, Professor of Surgery/Urology, Department of Urology, Laval University, Quebec, QC, CHUQ - L'Hotel-Dieu de Quebec, 11 Côte du Palais, Quebec QC GIR 2J6; yves.fradet@crhdq.ulaval.ca 